\title{
Two new Japanagromyza Sasakawa (Diptera: Agromyzidae) from Brazil
}

\author{
Viviane R. de Sousa \& Márcia S. Couri
}

Departamento de Entomologia, Museu Nacional, Universidade Federal do Rio de Janeiro. Quinta da Boa Vista, s/nº, São Cristóvão, Rio de Janeiro, 20940-040, RJ, Brazil. (sousavrodrigues@gmail.com)

Received 17 January 2017

Accepted 12 June 2017

DOI: $10.1590 / 1678-4766 e 2017032$

ABSTRACT. Japanagromyza Sasakawa, 1958 (Diptera, Agromyzidae) is poorly known from Brazil, with only three species recorded. This contribution increases the knowledge of the genus in Brazil, where two new species are described and illustrations of male and female adults and terminalia are presented. The material was collected in states of Mato Grosso, Mato Grosso do Sul and Rondônia and is deposited in the collections of Museu de Zoologia, Universidade de São Paulo and Museu Nacional, Universidade federal do Rio de Janeiro.

KEYWORDS. Brazilian species, insect, leaf-mining flies, neotropics, taxonomy.

Japanagromyza Sasakawa, 1958 is a very interesting genus of Agromyzidae (Diptera) with galling and leafmining species. Almost all valid species in the neotropics are associated with Fabaceae plants (BENAVENT-CoRAI et al., 2005). The gall-inducers species are still little known in the Neotropical Region. Two recent records are Japanagromyza lonchocarpi Boucher \& Hanson, 2006 forming galls on petiole in Lonchocarpus oligantus F.J. Herm. (Fabaceae) (BOUCHER \& HANson, 2006) and Japanagromyza inferna Spencer, 1973 on leaf in Centrosema virginianum L. in Brazil (SOUSA \& Couri, 2014).

The genus was originally described from Japan (SASAKAWA, 1958) and is traditionally considered to be close to Melanagromyza Hendel, 1920 and Agromyza Fallén, 1810 by similarities in external structures (SASAKAWA, 1961, 2010). A phylogenetic study made by SCHEFFER et al. (2007) where each of these genera were represented by one species, positioned Japanagromyza close to the other two. More species should be included in further analyzes to reveal a better understanding about the genus (LonSDALE, 2013). According to DEMPEWOLF (2004), Japanagromyza is a sister group of the tribe Ophiomyiini (that includes Ophiomyia Braschnicov, 1897, Hexomyza Enderlein, 1936, Tropicomyia Spencer, 1973, Kleinschmidtimyia Spencer, 1986 and Melanagromyza Hendel, 1920) based in the following characters: surstylus elongated, form of the phallus, cleaning comb on hind tibia and posterior spiracles of larvae. This comb of setae before the end of the hind tibiae was also noted by Tschirnhaus (1991) in Japanagromyza and Liriomyza Mik, 1894.

Japanagromyza species are usually uniform in external structures and chaetotaxy, but a few singular Neotropical species are yellow colored (SASAKAWA, 2010). These species were originally described in Geratomyza Spencer, 1973 (SPencer \& Stegmaier JR., 1973), and later synonymized with Japanagromyza by SPENCER (1984).

The genus has about 80 valid species worldwide distributed (LONSDALE, 2013), approximately 30 in the Neotropical Region (Martinez \& ETIENNE, 2002; ETIENNE \& Martinez, 2003; SASAKawa, 2005; Boucher \& Hanson, 2006). The Brazilian Japanagromyza are poorly known, although recent contributions increased the number of the known species to three: Japanagromyza macroptilivora Esposito \& Prado, 1993 known to São Paulo (EsPosito \& Prado, 1993), J. inferna Spencer from Rio de Janeiro (SousA \& Couri, 2014) and Japanagromyza sasakawai Monteiro, Carvalho-Filho \& Esposito, 2015 from the Amazonian Rain Forest in Pará (MonteIro et al., 2015).

In the present paper two new species from the Amazonian Rain forest, "Cerrado" and "Pantanal" biomes from Brazil are described.

\section{MATERIAL AND METHODS}

The specimens were collected in states of Mato Grosso, Mato Grosso do Sul and Rondônia (Brazil), where expeditions were made during the "SISBIOTA Diptera" project. This project had the purpose to characterize and mapping the diversity of the Diptera in unexplored areas of Brazil. The specimens were captured using Malaise traps and were preserved in alcohol $98 \%$, moved to the laboratory where they were mounted in entomological pins. All material was deposited at the collections of Museu de Zoologia, Universidade de São Paulo, São Paulo, Brazil (MZUSP) and Museu Nacional, Universidade Federal do Rio de Janeiro 
(MNRJ).

Male and female terminalia were clarified in $\mathrm{KOH}$ $10 \%$ for 48 hours, immerse in glycerin on blades for analysis under optical microscope and drawn using a camera lucida and after the study were stored in microvials. Digital images of the adults were made using a Leica MZ16 stereomicroscope and the software AutoMontage Pro by Syncroscopy, version 5.03.0061. The species identification was based in BOUCHER (2010) and Sousa \& Couri (2014) keys. The terminology followed Cumming \& WoOD (2009).

\section{RESULTS}

\section{Japanagromyza arcuaria sp. nov.}

(Figs 1-8)

LSID: urn:lsid:zoobank.org:act:0C254B13-7055-42E7BC9D-25B418B040D1

Type material. Holotype ${ }^{\lambda}$, BRASIL, RO [Rondônia], Campo Novo (Fazenda Amorim 1040'06”'S, 6329'00”'W 248m), Malaise trap - 6 m, holotype and 1ㅇ, 03-15.xii.2011, Amorim, Ament \& Riccardi cols. (MZUSP); BRASIL, MS [Mato Grosso do Sul], Corguinho, Taboco (Reserva Quinta

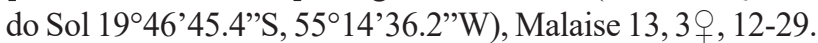
viii.2012, Lamas, Nihei \& eq. cols (MNRJ); (1946'40.8”S $\left.55^{\circ} 14^{\prime} 59.0^{\prime \prime} \mathrm{W}\right)$, Malaise 12, ㅇ, 12-29.ix.2012, Lamas, Nihei \& eq. cols, (MZUSP); Corumbá (B.E.P. Paratudal

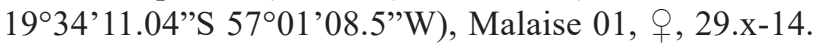
xi.2012, Lamas Nihei \& eq. cols. (MZUSP).

Etymology. The specific epithet refers to the presence of a sclerotized arc before the apex of the distiphallus.

Measurements. Male. Body length: $2.0 \mathrm{~mm}$; wing length: $1.5 \mathrm{~mm}$ (Fig. 1). Female Body length: $2.1 \mathrm{~mm}$; wing length: $1.7 \mathrm{~mm}$ (Fig. 2).

Color. Frons mat black, slightly reddish brown on basal half; the basal reddish brown occupies about $1 / 3$ of the frons; fronto-orbital plate and ocellar triangle shining black; upper shining dark orbit touching the outer vertical and inner vertical setae; lunule and face grey yellowish; clypeus slightly shiny brownish yellow; gena orange; antenna entirely brownish yellow; arista brown; palpus brown, with black setae apically; proboscis yellow; labellum yellow, with yellow setae; scutum and scutellum shining dark brown; postpronotum light yellow, with a median brown spot; notopleuron light yellow; anepimeron, anepisternum, katepimeron, katepisternum and meron dark brown; suture between anepisternum and anepimeron light yellow; haltere entirely pale yellow; calypter pale yellow, with margin and fringe black; wing clear, light yellow at base; legs yellow, except tip of mid and hind coxae, mid and hind tibiae and tarsi brown; pulvilli yellow; tergites $1+2$ entirely yellow, tergite 3 yellow with a brown spot centrally, tergite 4 yellow with a brown spot centrally and two spot laterally, tergite 5 , tergite 6 and terminalia entirely brown.

Head. Frons slightly visible above the eye margin in lateral profile; 2 reclinate ori and 2 reclinate ors, both very strong, the ori a little smaller; interfrontal hairs absent; orbital setulae erect in one row; eye bare; facial kell not differentiated; eye height/parafacialia+gena: 4; ocellar triangle long, reaching the second ori insertion level; ocellar setae long, parallel and directed forward; inner vertical setae long and strong; outer vertical setae strong and outwards directed; lunule high and straight, about $20 \%$ of frons length; clypeus narrow; epistoma high $0.03 \mathrm{~mm}$; first flagellomere rounded and finely pubescent; arista long, finely pubescent, almost the same length of the vertical height of eye; vibrissa long and strong measuring $2 / 3$ of the aristal length; one row of long and strong peristomals.

Thorax. Acrostichals in eight irregular rows; propleural present; prescutellar present; $0+2$ dorsocentrals, strong and similar in size; 1 presutural setae; 1 intra-alar; 1 supra-alar; 2 post-alars; 1 postpronotal; posthumeral absent; 2 notopelurals, similar in size; 2 long and strong pairs of scutellar setae, 1 sub-basal and 1 apical; katepisternum with small and fine setae and 1 long and strong posterior seta.

Wing. Subcostal vein joining $R_{1}$ before reaching Costal and the distal margin of $\mathrm{R}_{1}$ sinuous nearer junction; Costal extending to $\mathrm{M}_{1}$; wing tip near to $\mathrm{R}_{4+5}$; Costal sections 2-4: 0.66: 0.13: $0.2 ; \mathrm{R}_{4+5}$ straight and $\mathrm{M}_{1}$ slightly recurved; ultimate section of $\mathrm{CuA}_{1} 0.7$ the length of basal section; r-m at midpoint of $\mathrm{dm}$.

Legs. Fore tibia without posterodorsal seta, with one ventral apical seta; mid tibia with two posterodorsal setae on middle third and one apical ventral seta.

Male terminalia. Epandrium rounded with long setae (Fig. 3); cercus long with long setae; postgonite absent; surstylus triangular with about 32 spines; distiphallus with a sclerotized arc before apex (Figs 4, 5); ejaculatory apodeme short, at its larger part about 3.6 times wider than the constricted area at base (Fig. 6).

Oviscape: (Fig. 7); spermathecae (Fig. 8).

Distribution. States of Rondônia and Mato Grosso do Sul (Brazil).

Remarks. This new species runs to Japanagromyza spadix (Spencer, 1963) in the key (Sousa \& CourI, 2014), but is differentiated by the male terminalia morphology. Also is similar to Japanagromyza chapadensis sp. nov. in the wing length and the dark brown coloration of the body, but can be differentiated by the lunule and face grey yellowish, gena orange, antenna entirely brownish yellow, surstylus triangular with about 32 spines, distiphallus with a well sclerotized arc before apex and ejaculatory apodeme short.

\section{Japanagromyza chapadensis sp. nov.}

(Figs 9-11)

LSID: urn:1sid:zoobank.org:act:7F332025-59B0-434A8F6FACAD6303D39B

Type material. Holotype ỗ, BRASIL, MT [Mato Grosso]: Chapada dos Guimarães (Cerrado) [Trilha da Pedra - final (mirante), $\left.15^{\circ} 24^{\prime} 21.8^{\prime \prime} \mathrm{S} 055^{\circ} 50^{\prime} 07.5^{\prime \prime} \mathrm{W}\right]$, Malaise 

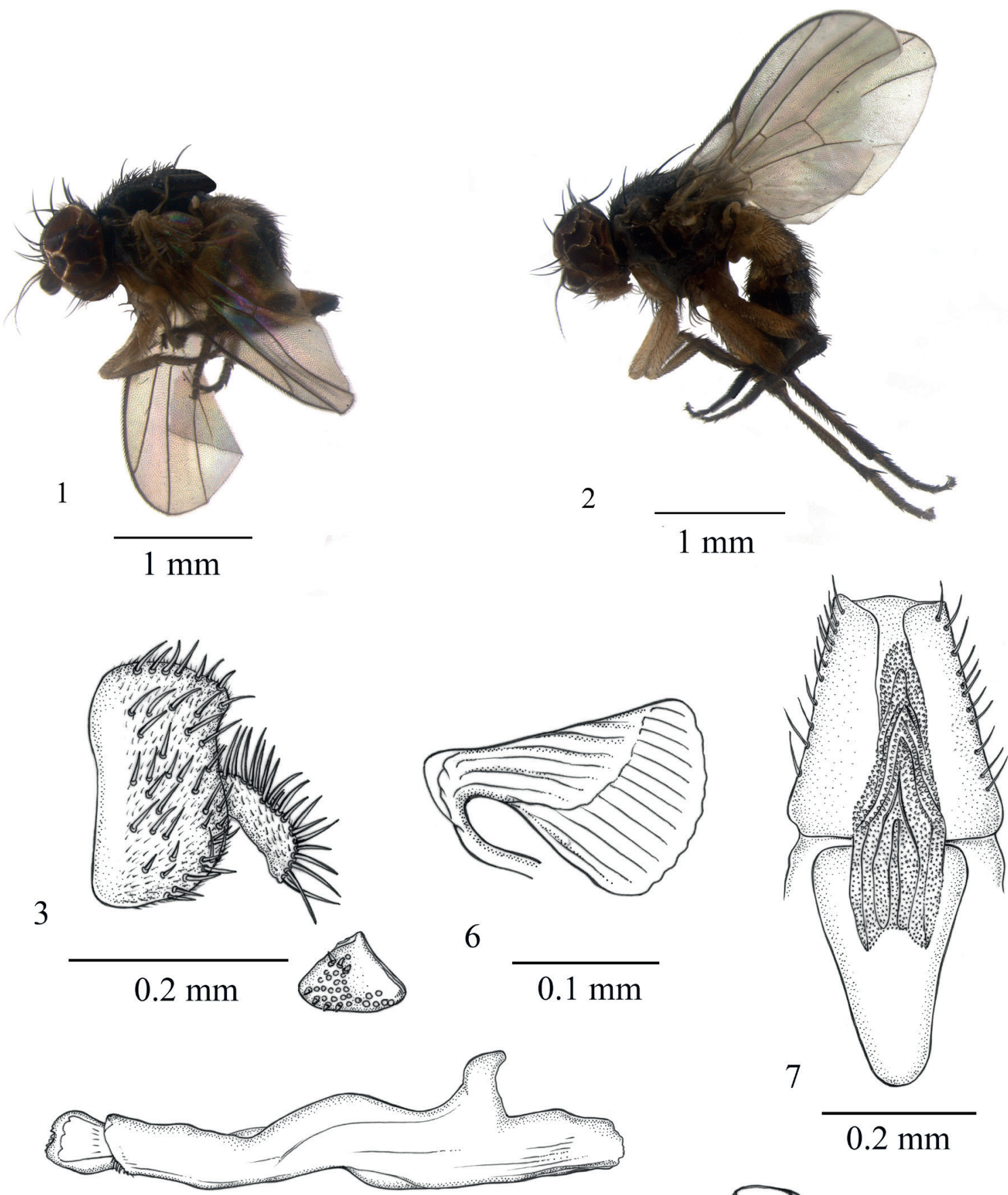

4

$$
0.2 \mathrm{~mm}
$$
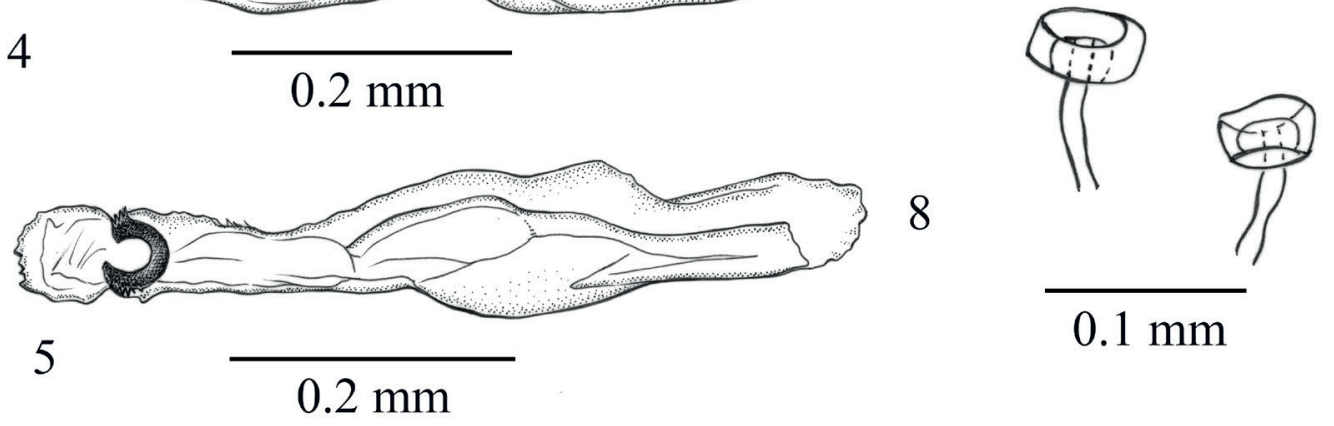

\section{$0.1 \mathrm{~mm}$}

Figs 1-8. Japanagromyza arcuaria sp. nov.: 1, adult male, lateral view; 2, adult female, lateral view; 3, epandrium; phallus: 4, lateral view; 5, ventral view; 6 , ejaculatory apodeme; 7 , oviscape; 8 , spermathecae. 
22, 18.iv-02.vii.2012, Lamas, Nihei \& eq. cols. (MZUSP). Etymology. The specific epithet refers to the type locality, Chapada dos Guimarães, where the holotype was collected.

Measurements. Male: Body length: $2.0 \mathrm{~mm}$; wing length: $1.5 \mathrm{~mm}$ (Fig. 9). Female: unknown.

Color. Frons mat black weakly shining, with basal half orange; fronto-orbital plate weakly shining black; upper shiny dark orbit touching the outer vertical and inner vertical setae; ocellar triangle black, greyish pollinose; lunule grey; face greyish brown; clypeus black subshining; gena dark brown; scape and pedicel light yellow; first flagellomere brown with some orange areas; arista brown; palpus yellow, with black setae apically; proboscis yellow; labellum yellow, with yellow setae; scutum and scutellum shining dark brown; postpronotum and all pleurae dark brown; suture between anepisternum and anepimeron light yellow; haltere entirely light yellow; calypters yellow, with margin and fringe black; wing clear, light yellow at base; legs yellow, mid and hind tibia and tarsi brown; pulvilli yellow; tergites $1+2$ entirely yellow, tergite 3 yellow with a brown spot centrally, tergites 4-6 and terminalia entirely brown.

Head. Frons slightly visible above the eye margin in lateral profile; 2 reclinate ors and 2 inclinate ori, similar in size; interfrontal hair absent; orbital setulae slightly reclinate in one row; facial keel undifferentiated; eye height/ gena+parafacialia: 4; ocellar triangle long, endind before the second ori insertion level; lunule high and straight, about $15 \%$ of frons length; clypeus rounded; epistoma not visible; first flagellomere slightly long and finely pubescent; arista long, plumose, almost the same length of the vertical height of eye; vibrissa short, measuring about $1 / 3$ the aristal length; one row of fine peristomals.

Thorax. Acrostichals in ten irregular rows; propleural present; prescutellar present; $0+2$ dorsocentrals, all broken; 1 presutural; 1 intra-alar; 1 supra-alar; 2 post-alars; 1 postpronotal; posthumeral absent; 2 notopleurals, the anterior longer than the posterior one; 2 long and strong pairs of scutellar setae, 1 sub-basal, 1 apical; katepisternal with medium and fine setae and 1 long and strong posterior seta.

Wing. Subcostal vein joining $\mathrm{R}_{1}$ before reaching the Costal and the distal margin of $\mathrm{R}_{1}$ sinuous nearer at junction; wing tip nearer to $\mathrm{R}_{4+5}$; Costal sections 2-4 in proportion: $0.5: 0.33: 0.16 ; \mathrm{R}_{4+5}$ and $\mathrm{M}_{1}$ slightly recurved; ultimate section of $\mathrm{CuA}_{1} 0.75$ the length of basal section; $\mathrm{r}-\mathrm{m}$ basal to midpoint of $\mathrm{dm}$.

Legs. Fore tibia without posterodorsal seta; mid tibia with two posterodorsal setae on middle third.

Male terminalia. Epandrium rounded with long setae; cercus long with long setae; surstylus long with about 44 strong spines; hypandrium long and Y-shaped; phallapodeme almost the same size length of the hypandrium; mesophallus sclerotized; distiphallus long, enlarged at base and bifurcated (Figs 10, 11); ejaculatory apodeme very large, at its larger part about 4.9 times wider than the constricted area at base (Fig. 12).

Distribution: state of Mato Grosso (Brazil).
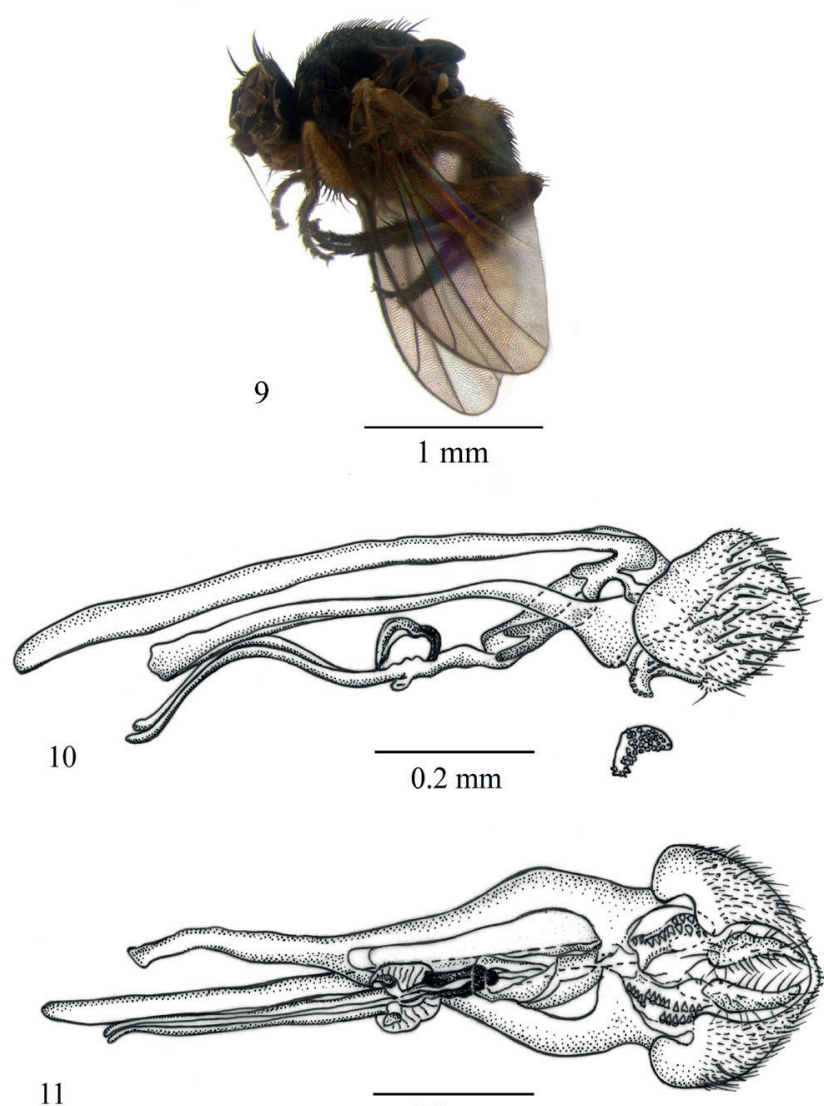

11

$0.2 \mathrm{~mm}$

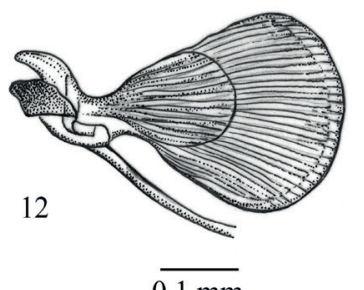

$\overline{0.1 \mathrm{~mm}}$

Figs 9-12. Japanagromyza chapadensis sp. nov.: 9, adult male lateral view; 10, phallus lateral view; 11, phallus ventral view; 12 , ejaculatory apodeme.

Remarks. This new species morphologically resembles $J$. arcuaria sp. nov. in wing length and color of the body, but can be differentiated by the grey lunule, face greyish brown, gena dark brown, scape and pedicel light yellow and first flagellomere brown with some orange areas. Besides, the male terminalia has the surstylus long with about 44 strong spines, hypandrium long and Y-shaped, distiphallus long, enlarged at base and bifurcated and ejaculatory apodeme very large.

Acknowledgments. The authors are grateful to Carlos Einicker Lamas (Museu de Zoologia, Universidade de São Paulo) and Silvio Nihei (Instituto de Biologia, Universidade de São Paulo) for the opportunity to participate on the SISBIOTA project. We thank Luiz Antonio Alves da Costa (Museu Nacional, Universidade Federal do Rio de Janeiro) for the final art of the drawings. Thanks also to Conselho Nacional de Desenvolvimento Científico e Tecnológico (CNPq, process number 563256/2010-9) and Fundação de Amparo à Pesquisa do Estado de São Paulo (FAPESP) (Process number 2010/52314-0) for the support to the SISBIOTA Diptera Project and for the financial supports (VRS: MsC/CNPq, process: 114102988; MSC: CNPq, process: 300382/2010-3). 


\section{REFERENCES}

Benavent-Corai, J.; Martinez, M. \& Jiménez-Peydró, R. 2005. Catalogue of the hosts-plants of the world Agromyzidae (Diptera). Bollettino di Zoologia Agraria e di Bachicoltura, Serie II (37):1-96 (Supplementum).

Boucher, S. 2010. Agromyzidae (leaf-mining flies). In: Brown, B. V.; Borkent A.; Cumming J. M.; Wood, D. M.; Woodley, N. E. \& Zumbado, M. A. eds. Manual of Central American Diptera. Ottawa, NRC Research Press, p. 1057-1071.

Boucher, S. \& Hanson, P. 2006. A new Costa Rican species of Japanagromyza (Diptera: Agromyzidae) forming galls on Lonchocarpus (Fabaceae). Proceedings of the Entomological Society of Washington 108(1):9-13.

Cumming, J. M. \& Wood, D. M. 2009. Adult morphology and terminology. In: Brown, B. V.; Borkent, A.; Cumming, J. M.; Wood, D. M.; Woodley, N. E. \& Zumbado, M. eds. Manual of Central American Diptera. Ottawa, NRC Research Press, Volume 1, p. 9-50.

DEMPEWOLF, M. 2004. Arthropods of Economic Importance - Agromyzidae of the World. ETI. Amsterdam, University of Amsterdam, Available at $<$ http://wbd.etibioinformatics.nl/bis/agromyzidae $>$. Accessed on: 18 Nov. 2016.

Esposito, M. C. \& Prado, A. P. 1993. New species of Japanagromyza and Galiomyza (Dipt., Agromyzidae) from Brazil. Entomologist's Monthly Magazine 129:239-243.

Etienne, J. \& Martinez, M. 2003. Les Agromyzidae de Guadalupe: espèces nouvelles et notes additionelles (Diptera). Nouvelle Revue d'Entomologie (nouvelle série) (3):249-272.

LonsDale, O. 2013. Japanagromyza Sasakawa (Diptera: Agromyzidae) of Africa. Zootaxa 3709(5):445-460.

Martinez, M. \& Etienne, J. 2002. Liste systématique et biogéographique des Agromyzidae (Diptera) de la région néotropicale. Bolletino di Zoologia Agraria e di Bachicoltura, Serie II (34):25-52.
Monteiro, N. J. S.; Carvalho-Filho, F. S. \& Esposito, M. C. 2015. A new species of Japanagromyza Sasakawa (Diptera: Agromyzidae) from the Brazilian Amazon with notes on biology. Zootaxa 3919(3):493-500.

SASAKAWA, M. 1958. The female terminalia of the Agromyzidae, with description of a new genus (I). Scientific Reports of the Saikyo University, Agriculture 10:133-150.

SASAKaWA, M. 1961. A study of the Japanese Agromyzidae (Diptera) Part 2. Pacific Insects 3(2-3):307-472.

Sasakawa, M. 2005. The Neotropical Agromyzidae (Insecta: Diptera). Part 6. New or little-known species from El Salvador and Guatemala. Species Diversity 10:151-169.

SASAKAWA, M. 2010. A review of the Oriental Japanagromyza Sasakawa (Diptera: Agromyzidae), with descriptions of four new species. Zootaxa 2485:16-32.

SousA, V. R. \& CourI, M. S. 2014. Redescription of Japanagromyza inferna Spencer, first recorded from Brazil, and key to the Neotropical species of Japanagromyza Sasakawa (Diptera, Agromyzidae). ZooKeys 374:45-55.

Spencer, K. A. 1984. The Agromyzidae (Diptera) of Colombia, including a new species attacking potato in Bolivia. Revista Colombiana de Entomología 10:3-33.

Spencer, K. A. \& Stegmaier, C. E. Jr. 1973. The Agromyzidae of Florida with a supplement on species from the Caribbean. Florida Department of Agriculture and Consumer Services, Gainesville. Arthropods of Florida 7:1-205.

Scheffer, S. J.; Winkler, I. S. \& Wiegmann, B. M. 2007. Phylogenetic relationships within the leaf-mining flies (Diptera: Agromyzidae) inferred from sequence data from multiple genes. Molecular Phylogenetics and Evolution 42:756-775.

TSCHIRNHAUS, M. VON. 1991. New results on the ecology, morphology, and systematics of Agromyzidae (Diptera). In: Weismann, L.; OrszáGH, I. \& Pont, A. C. eds. Proceedings of the Second International Congress of Dipterology. The Hague, SPB Academic Publishing, p. 285-313. 